\title{
A 74-year-old soybean allergy woman with anaphylaxis after propofol injection
}

\author{
AS Jang ${ }^{*}$, C-S Park, DJ Kim, S-W Park \\ From Food Allergy and Anaphylaxis Meeting (FAAM 2013) \\ Nice, France. 7-9 February 2013
}

\section{Background}

Adverse immune responses to foods affect approximately $3 \%$ to $4 \%$ of adults in westernized countries and appear to have increased in prevalence. Food induced allergic reactions are responsible for a variety of symptoms and disorders involving the skin and gastrointestinal and respiratory tracts and can be attributed to IgE-mediated and non--IgE-mediated (cellular) mechanisms.

\section{Methods}

A previously healthy 74-year-old woman visited our hospital to undergo esophagogastroduodenoscopy for a checkup. She had an allergy to soybean. Approximately $1 \mathrm{~min}$ following administration of intravenous propofol, stridor was heard and oxygen saturation fell to $56 \%$ on pulse oximetry. We decided to stop the exam, and tried to remove the endoscope. But, the endoscope has stuck in her throat and it was not pulled out. We removed the endoscope by compulsion. After 10 seconds endoscope removal, severe wheezing was heard and her oxygen saturation fell to $56 \%$. The larynx was observed using a laryngoscope for endotracheal intubation. At that time marked swelling and severe edema of the epiglottis and heavy mucoid secretion in the epiglottis extending to the arytenoids cartilage was detected. Immediately $1 \mathrm{mg}$ epinephrine was administered subcutaneously, together with $150 \mathrm{mg}$ intravenous methylprednisolone was infused. Because the patient was not improved in symptom after 1 minute, $1 \mathrm{mg}$ epinephrine was administered intravenously. After 1minute, her oxygen saturation recovered to $98 \%$ and the wheezing was subsided.

\section{Results}

The patient underwent skin-prick testing 14 days after the event. Skin-prick tests with dilutions of propofol and

Soonchunhyang University Bucheon Hospital, Bucheon, Republic of Korea
20\% Intralipid (Smoflipid, Fresenius Kabi, Bad Homburg, Germany), and phenol showed immediate reaction for propofol and $20 \%$ Intralipid.

\section{Conclusion}

So we suspected soybean in intralipid, a component of propofol as the cause of this anaphylaxis, because she had a food allergy history to soybean and she showed positive responses to intralipid and propofol on skin-prick testing. She was informed of the results and of the risk for anaphylaxis if re-exposed to propofol or nutritional supplements containing soybean in the future.

\section{Disclosure of interest}

None declared.

Published: 25 July 2013

doi:10.1186/2045-7022-3-S3-P147

Cite this article as: Jang et al: A 74-year-old soybean allergy woman with anaphylaxis after propofol injection. Clinical and Translational Allergy 2013 3(Suppl 3):P147.

Submit your next manuscript to BioMed Central and take full advantage of:

- Convenient online submission

- Thorough peer review

- No space constraints or color figure charges

- Immediate publication on acceptance

- Inclusion in PubMed, CAS, Scopus and Google Scholar

- Research which is freely available for redistribution

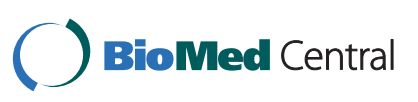

(c) 2013 Jang et al; licensee BioMed Central Ltd. This is an Open Access article distributed under the terms of the Creative Commons Attribution License (http://creativecommons.org/licenses/by/2.0), which permits unrestricted use, distribution, and reproduction in any medium, provided the original work is properly cited. 